\title{
CIRCULAÇÃO HORIZONTAL EM ESPAÇOS ACESSÍVEIS COM DIMENSÕES REDUZIDAS: UM ESTUDO DE CASO EM UM CONJUNTO HABITACIONAL POPULAR
}

\author{
NASCIMENTO, Cristiane Mirelle Alves do (1); \\ BARROS, Bruno (2). \\ (1) Universidade Federal de Pernambuco, Bacharel. \\ e-mail:crisnascimento.mirelle@hotmail.com \\ (2) Universidade Federal de Pernambuco, Mestre. \\ e-mail:barros_bruno@hotmail.com
}

\begin{abstract}
RESUMO
O presente trabalho trata de uma análise da circulação horizontal das moradias populares destinadas a moradores cadeirantes de baixa renda, através de um estudo de caso. O objetivo foi o verificar a eficácia dos espaços de circulação proporcionados no local, além de propor recomendações acessíveis para o espaço. Com o intuito de coletar dados dimensionais fora utilizado o Método de Avaliação da Circulação Horizontal Interna dos Ambientes - MACHIA. Como resultado, identificou-se que, apesar da unidade habitacional ser classificada como acessível, não se identifica uma circulação adequada para um cadeirante.
\end{abstract}

Palavras-chave: acessiblidade; circulação horizontal; moradia popular.

\begin{abstract}
The present research deals with an analysis of the horizontal circulation of the popular dwellings destined to low income residents, through a case study. The objective was to verify the effectiveness of the circulation spaces provided in the place, besides proposing recommendations accessible for the space. In order to collect dimensional data, it was used the Internal Horizontal Circulation of Environments Assessment Method - MACHIA. As a result, it has been identified that, although the housing unit is classified as accessible, adequate movement for a wheelchair is not identified.
\end{abstract}

Keywords: accessibility; horizontal circulation, public Housing.

\section{INTRODUÇÃO}

Com o crescimento de programas e políticas públicas habitacionais destinadas à população de baixa renda, que possuem o intuito de diminuir o déficit habitacional, cresceu também a necessidade de estudos avaliativos relacionados à acessibilidade e circulação horizontal dos ambientes com dimensões reduzidas. A fim de analisar a situação da circulação horizontal dos apartamentos destinados aos moradores cadeirantes, beneficiados do Auxílio Moradia em um estudo de caso, buscou-se compilar informações sobre normas e estudos que 


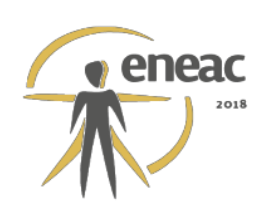

possuem como objetivo a promoção da Acessibilidade em ambientes com dimensões reduzidas.

Cidadãos cadeirantes, por exemplo, enfrentam diversos desafios em sua rotina, não apenas nos ambientes públicos, mas também em ambientes domésticos que são projetados sem a consideração da diversidade dos possíveis usuários. Para produzir ambientes que venham atender tais necessidades, o design deve estar atrelado à qualidade, com o objetivo de adequar ou fornecer produtos que atendam positivamente através de seus aspectos funcionais e estéticos. Para que isso seja possível, é indispensável levar em conta os aspectos antropométricos do usuário para qual se destina o produto/ambiente que, segundo Barros et al (2004), essa consideração resulta de forma positiva, gerando conforto, eficiência, segurança e menor probabilidade de acidentes.

Como intuito de garantir moradia ao maior número de famílias concentrados em um único conjunto, os projetos habitacionais recorrem à redução e padronização dimensional das habitações, que está diretamente ligada ao comprometimento do desempenho das atividades dos usuários, causando na maioria das vezes transtornos à sua rotina. Os conjuntos habitacionais fornecidos as famílias carentes pela Prefeitura da Cidade deste estudo de caso são exemplos de espaços com dimensões reduzidas e padronizadas. Logo, se fez necessária a análise da circulação desses espaços, com o intuito de verificar se estão de acordo com os critérios estabelecidos pelo Foro Nacional de Normalização Brasileira de Normas Técnicas (ABNT), através da NBR 9050:2015.

Os objetivos que impulsionaram o estudo de caso foi o de prover recomendações dimensionais de caráter acessível para as moradias populares, além de compreender 0 ambiente doméstico destinado para um morador cadeirante, analisá-lo de acordo com as normas e identificar as inadequações da circulação permitida no local.

\section{FUNDAMENTAÇÃO TEÓRICA}

Segundo a Associação de Normas Técnicas (ABNT) por meio da NBR 9050:2015, a Acessibilidade se dá pela condição e possibilidade de alcance, percepção e entendimento para a utilização do ambiente ou objeto, de forma que seja compreendido e utilizado por pessoas com limitações ou não, seja na zona urbana ou rural. A edificação acessível, objeto, sistemas, mobiliário ou transportes acessíveis trazem benefícios não somente as pessoas com limitações físicas, mas atendem as necessidades de todos os possíveis usuários, de forma plena, satisfatória e respeitosa.

A falta da Acessibilidade gera barreiras que impedem o cidadão de usufruir de seus direitos com qualidade, considerada como um dos maiores desafios a serem enfrentados. Segundo Prado (2001 apud FREGOLENTE, 2008), são classificadas como barreiras visíveis e invisíveis. A primeira se dá pelas barreiras concretas, ou barreiras arquitetônicas, que são todos os obstáculos que impedem a circulação de qualidade, como por exemplo: a falta de rampas, a presença de desníveis, falta de calçamento e presença de degraus, que dificultam a circulação nos espaços para idosos, gestantes, pessoas com limitação visual ou para aquelas que fazem uso da cadeira de rodas. As barreiras invisíveis denominam a visão preconceituosa de incapacidade e invalidez que a sociedade, muitas vezes, possui em relação às pessoas com limitações. Dessa forma, atrapalham a inclusão social dos indivíduos com limitações, roubando-os a oportunidade de exercer suas atividades perante a sociedade. A presença das barreiras visíveis está totalmente ligada à visão criada pela sociedade, a sua eliminação contribui para o fim das barreiras invisíveis e para a qualidade de vida das pessoas com necessidades específicas, garantindo assim sua autonomia e 


\section{rision}

passando a serem membros ativos na sociedade (COHEN; DUARTE, 2001 apud FREGOLENTE, 2008).

Com base no Censo Demográfico de 2010, no Brasil cerca de 45,6 milhões de Brasileiros possui algum tipo de limitação, equivalente a $23,9 \%$ da população Nacional. O tipo de deficiência mais declarado foi a visual com aproximadamente 35,7 milhões de pessoas, em segundo lugar a deficiência motora com aproximadamente 13,2 milhões de pessoas, em terceiro a deficiência auditiva com cerca de 9,7 milhões de pessoas, e em quarto o tipo de deficiência mental/intelectual, com o número aproximado de 2,6 milhões de pessoas (Figura 01).

Figura 01: Gráfico da população residente por tipo de deficiência.

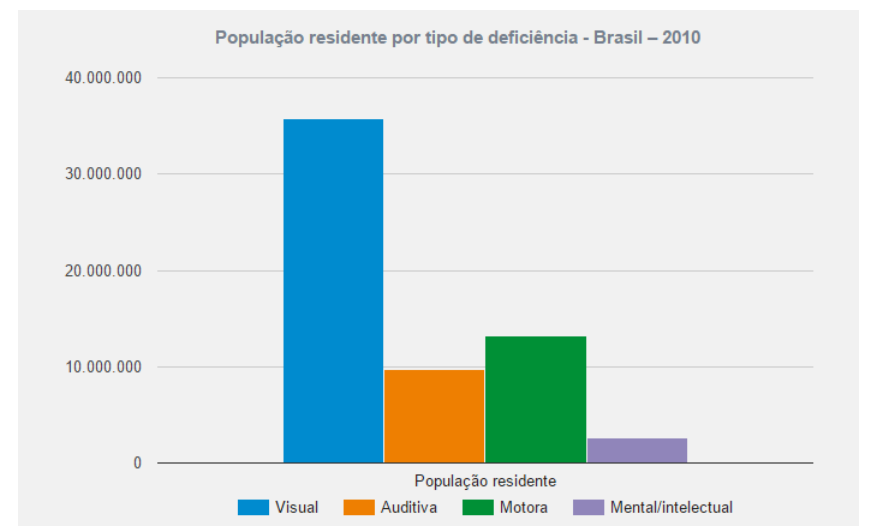

Fonte: IBGE, Censo Demográfico 2010.

$\mathrm{Na}$ cidade onde se localiza o estudo de caso, foram contabilizados que, dos aproximados 1,6 milhão de habitantes, cerca de 40.543 mil pessoas (aproximadamente $25,7 \%$ da população) possuem deficiência motora com grande dificuldade. Sendo cerca de $26,5 \%$ da população com rendimento domiciliar per capita de até $1 / 2$ (meio) salário mínimo, o que nos indica que boa parcela dos cidadãos são de baixa renda, tendo em vista que ter alguma necessidade específica aumenta o custo de vida pela necessidade de cuidados especiais, dificultando ainda mais a obtenção de uma vida com qualidade e dignidade.

U município tem a obrigação de legislar sobre os assuntos de interesse local, por advento da Constituição Federal de 1988, as cidades devem garantir aos seus habitantes formas de deslocamento para as mais diversas necessidades (FREGOLENTE, 2008). Cumprir as normas técnicas de acessibilidade e os princípios do design inclusivo é primordial, pois nos assegura a igualdade de oportunidades e qualidade de vida dos cidadãos. A NBR 9050/2015 promove a acessibilidade a edificações, mobiliário, espaços e equipamentos urbanos ou privados, apresentando critérios e parâmetros técnicos a serem considerados no projeto, construção ou adaptação de equipamentos, edificações e mobiliário. Para garantir um correto desenvolvimento dos ambientes com características acessíveis, é necessária a utilização dos parâmetros e critérios de dimensões estabelecidos pela norma, no estudo foram levados em consideração apenas os parâmetros técnicos que envolvem a circulação horizontal do espaço com o usuário que faz uso da cadeira de rodas.

Tendo como estudo o usuário cadeirante, se faz necessário considerar as dimensões referenciais para o deslocamento de pessoas com cadeiras de rodas. A NBR 9050/2015 (p. 08) na seção 4.2. Pessoas em cadeira de rodas (P.C.R.), seguido pela subseção 4.2.1 


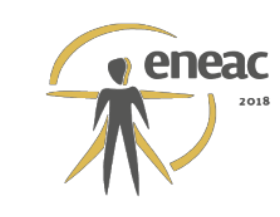

Cadeiras de rodas, apresentam dimensões referenciais para cadeiras de rodas manuais ou motorizadas (Figura 02).

Figura 02: Cadeira de rodas manual, motorizada e esportiva (dimensões em metros).

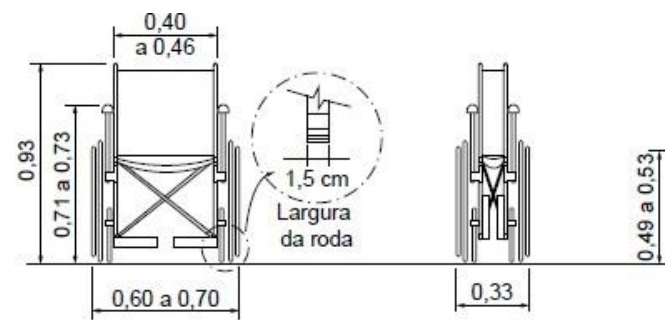

a) Vista frontal aberta

b) Vista frontal fechada

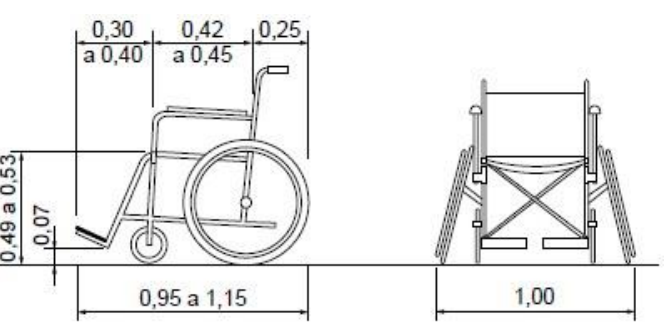

c) Vista lateral d) Vista frontal Cadeira cambada

Fonte: NBR9050, 2015.

Para o módulo de referência, tópico 4.2.2, considera-se a projeção de 0,80 m por 1,20 m no piso, ocupada por uma pessoa utilizando cadeira de rodas seja ela motorizada ou não, exemplificada pela Figura 03 (NBR 9050/2015, p.08).

Figura 03: Dimensões do módulo de referência (dimensões em metros).

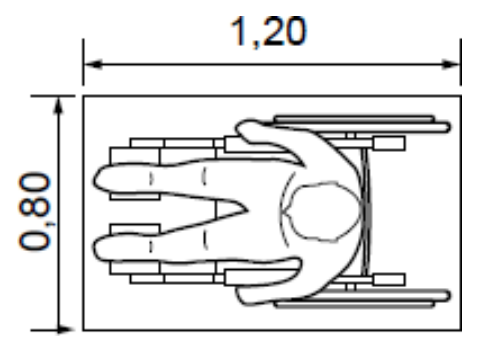

Fonte: NBR9050, 2015.

Para uma melhor visualização das informações estabelecidas pela norma, são compiladas na Tabela 01 as dimensões mínimas necessárias para uma circulação confortável do cadeirante em ambientes internos, sejam públicos ou privados de acordo com a NBR 9050/2015 apresentadas na seção 4.2 Pessoas em cadeira de rodas (P.C.R.).

Tabela 1 - Informações dimensionais para deslocamento.

\begin{tabular}{|l|c|}
\hline \multicolumn{1}{|c|}{ Deslocamento em linha reta } & $\begin{array}{c}\text { Largura } \\
\text { (metros) }\end{array}$ \\
\hline Uma pessoa em cadeira de rodas & $0.90 \mathrm{~m}$ \\
\hline Um pedestre e uma pessoa em cadeira de rodas & $1.20 \mathrm{a} 1.50 \mathrm{~m}$ \\
\hline Duas pessoas em cadeira de rodas & $1.50 \mathrm{a} \mathrm{1.80 \textrm {m }}$ \\
\hline Transposição de obstáculos isolados (extensão $\geq 0,40 \mathrm{~m}$ ) & $0.80 \mathrm{~m} \mathrm{a} \mathrm{0.90m}$ \\
\hline Corredores de uso comum (extensão até 4,00 m a 10,m) & $0,90 \mathrm{a} 1.20 \mathrm{~m}$ \\
\hline Vãos das portas quando abertas & $0.80 \mathrm{~m}$ \\
\hline
\end{tabular}

Fonte: NBR9050/2015. 


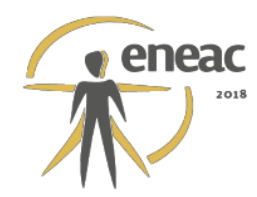

Considerando as atividades domésticas onde é necessária a movimentação do usuário, a subseção 4.3.4 apresenta a área para manobra de cadeiras de rodas sem deslocamento: "As medidas necessárias para a manobra de cadeira de rodas sem deslocamento, (Figura 04), são: a) para rotação de $90^{\circ}=1,20 \mathrm{~m} \times 1,20 \mathrm{~m}$; b) para rotação de $180^{\circ}=1,50 \mathrm{~m} \times 1,20$ $\mathrm{m} ; \mathrm{c})$ para rotação de $360^{\circ}=$ círculo com diâmetro de 1,50 m" (ABNT, 2015).

Figura 04: Área para manobra de cadeira de rodas sem deslocamento (dimensões em metros).

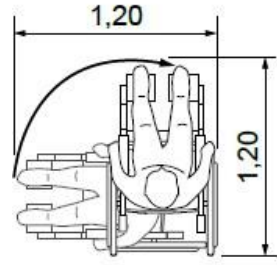

a) Rotaçäo de $90^{\circ}$

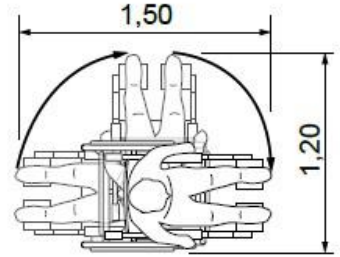

b) Rotação de $180^{\circ}$

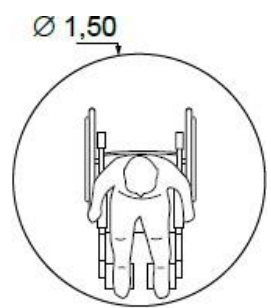

c) Rotaçäo de $360^{\circ}$

Fonte: NBR9050 (2015).

Além de tais informações dimensionais, foram consideradas para a análise as recomendações apresentadas para os banheiros compilados na seção 7 que envolvem sanitários, banheiros e vestiários, considerando as áreas de transferência necessárias para uma circulação confortável. Na norma NBR 9050/2015 não são apresentadas dimensões quanto à circulação do cadeirante em seu próprio quarto, porém foram consideradas as recomendações apresentadas para quartos de hospedagem, compilados na seção 10.9.3.

Com a compilação das recomendações que se refere à circulação temos em mãos um conteúdo de parâmetros básicos para o entendimento de um ambiente acessível. O uso dessas recomendações nos garante bons resultados nos projetos de habitação para pessoas em cadeira de rodas, pois a NBR 9050 trata da adequação das edificações com o objetivo de promover a acessibilidade, sendo um bom instrumento de ajuda para 0 desenvolvimento do presente projeto na avaliação e correção do ambiente em estudo.

No projeto de uma edificação é necessário que a equipe responsável pelo projeto leve em consideração as características físicas em relação às atividades que serão desenvolvidas no ambiente. Além do usuário que irá utilizar, as suas condições físicas e sua diversidade; como no caso das habitações padronizadas de caráter multifamíliar que são direcionadas para um grande número de moradores (GRAEFF, 1986 apud COSTA, 2016). Com isso, os projetistas devem ter conhecimento dos limites dimensionais que serão impostos com relação às proporções corporais dos possíveis usuários.

Neste sentido, o ergonomista possui papel fundamental na fase de planejamento, pois deverá analisar atentamente cada ambiente com foco na sua função prática e de como o ambiente precisa atender as necessidades do usuário, da sua interação com o espaço, levando em consideração a sua opinião, que por sua vez podem ser positivas ou negativas.

A redução dimensional das moradias é resultado da industrialização, sendo a habitação padronizada um dos grandes problemas enfrentados pela população. Esta redução implica na organização do mobiliário, que possui ligação direta com o conforto do usuário no ambiente. De acordo com Folz (2002 apud SOUZA, 2012), caso os móveis não estejam em concordância com as dimensões do ambiente, o desempenho da moradia estará comprometido, isto é, ambientes mal planejados e mobiliados de forma inapropriada podem gerar congestionamento do espaço comprometendo a circulação horizontal do ambiente. 


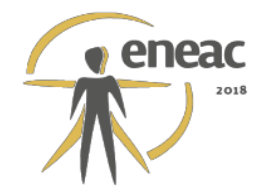

Podemos nos utilizar da antropometria em vários setores do design, gerando assim produtos com garantia de eficiência, segurança e usabilidade. Para Barros e Seabra (2013), deve-se considerar os dados antropométricos adequados e relacionados aos percentis corretos para cada projeto. Os problemas encontrados nos ambientes, em sua maioria, estão ligados a incorreta ou não utilização das dimensões humanas no projeto, fator este que deve ser sempre considerado na fase projetual de ambientes construídos, já que abrange todo o ser humano(BOUERI, 2008 apud BARROS, 2016).

A circulação de um ambiente deve ser projetada considerando o dimensionamento humano, onde as dimensões do corpo maior é que devem servir como elemento básico para o projeto de edificações. Se a circulação satisfaz uma pessoa com grandes dimensões, ela certamente atenderá a uma maior quantidade de usuários, logo o ambiente possuirá qualidade em seu desempenho. Nesta questão comparamos que, se o ambiente é acessível para um cadeirante, que necessita de maior área para circulação horizontal devido as dimensões da cadeira de rodas, certamente será acessível para usuários que não possuem ou que possuem outros tipos de necessidades (BARROS e SEABRA,2013; PANERO e ZELNIK,2008).

\section{METODOLOGIA}

O Método de Avaliação da Circulação Horizontal Interna dos Ambientes - MACHIA, estruturado por Barros (2009), foi o método adotado para a análise da circulação horizontal do ambiente. Para os autores Barros e Seabra (2013), o princípio do MACHIA é perceber os aspectos antropométricos avaliados por meio de pesquisas e compará-los através de uma simulação da circulação horizontal. Propõe simulações gráficas das situações do usuário interagindo em cada espaço, de forma que o usuário é representado por modelos antropométricos em plantas baixas, inseridos no layout de ambientação, fornecendo também dados concretos que poderão ser utilizados para estudos do ambiente construído. Para a classificação da circulação, foram consideradas o módulo de referencia apresentado pela NBR 9050. Na Figura 05 temos como medida referencial para a cadeira de rodas: 0,60 à $0,70 \mathrm{~m}$ de largura e 0,95 à $1,15 \mathrm{~m}$ de profundidade.

Figura 05: Campos de circulação em linha reta

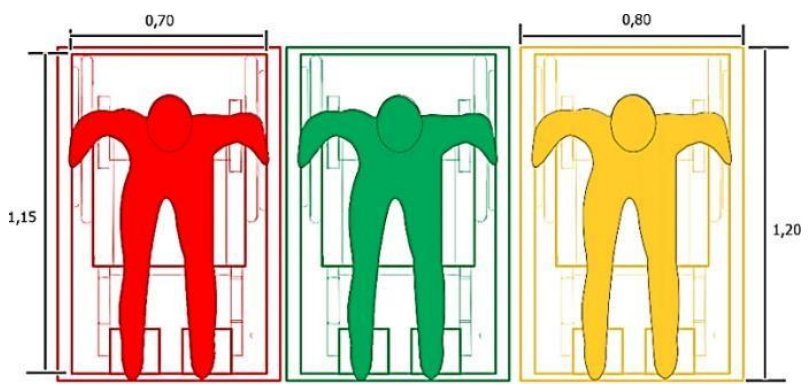

Fonte: Barros (2016)

Logo, foram consideradas que as áreas que ultrapassassem a linha de $0,70 \times 1,15 \mathrm{~m}$ seriam consideradas como inadequadas (vermelho), já que impossibilita ou interfere na qualidade da circulação. Para áreas que tocassem a zona de 0,80x1,20 m serão consideradas como situação de atenção (amarelo) e para as áreas de circulação que não tocarem a zona de toque serão consideradas como adequadas (verde). 


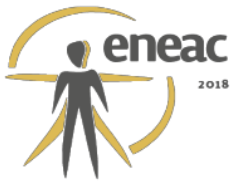

O método pode ser aplicado tanto em fase de projetos, quanto em estudos avaliativos de ambientes já construídos, uma vez que, de acordo com Costa Filho et al. (2003, apud BARROS; SEABRA, 2013), analisar os ambientes em fase de uso é uma forma de investigação de desajustes da relação do usuário com o ambiente. Nos casos onde ainda está em fase projetual, o método é aplicado em plantas baixas e no layout do ambiente que será proposto, com o intuito de verificar se o projeto está de acordo com os fatores antropométricos.

\section{RESULTADOS}

Com o objetivo de analisar um ambiente padronizado destinado para moradores cadeirantes e de baixa renda em habitação com caráter popular, houve a escolha de um apartamento acessível do Conjunto Habitacional selecionado como estudo de caso (Figura 06). O conjunto possui dez blocos de 32 apartamentos, tendo total de 320 moradias destinadas a 179 famílias provenientes de áreas de risco e 141 formadas por ex-moradores da ocupação desde 1998.

Figura 06: Conjunto habitacional (A), quarto do morador (B), sala (C) e banheiro (D).

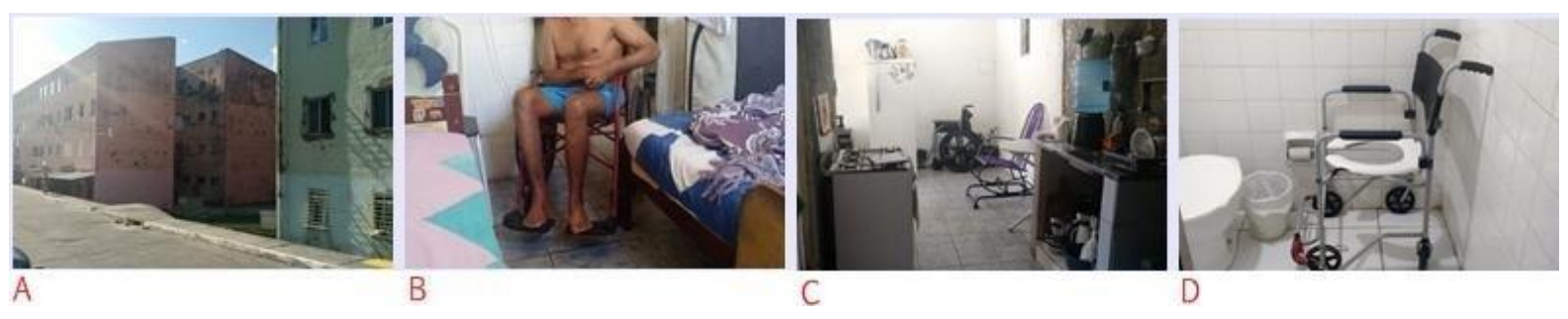

Fonte: capturado pelos autores para a pesquisa.

A moradia selecionada como estudo de caso foi destinada para uma família que na época era composta por quatro pessoas, sendo dois deles cadeirantes. Atualmente, os números de moradores são três, sendo um deles cadeirante. O apartamento analisado foi o de № 05 localizado no térreo do bloco B, com área de $41,6 \mathrm{~m}^{2}$, o qual apresenta dois quartos, sala com ambiente dividido para a cozinha e área de serviço com um banheiro.

Conhecer o objeto de estudo, entender e analisar como se dá a relação do usuário com o ambiente construído é primordial para qualquer análise. Neste primeiro foi compreendido um pouco da realidade na qual os usuários cadeirantes que compõem o grupo de beneficiários de programas de habitação popular estão inseridos, sendo assim partiu-se para a análise de circulação do ambiente tendo como base as normas e métodos já apresentados.

Após os registros fotográficos e observação do ambiente em uso, foi realizada uma coleta de informações referentes às dimensões de circulação horizontal que o ambiente oferece. Buscou-se coletar o máximo de informações possíveis, como as dimensões dos móveis e a distância entre eles, com o intuito de representar o ambiente da melhor forma possível (Fig. 07). 


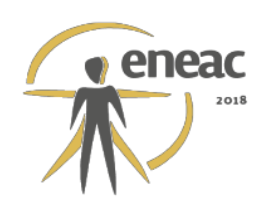

Figura 07: Planta baixa com dimensões dos móveis e área para circulação

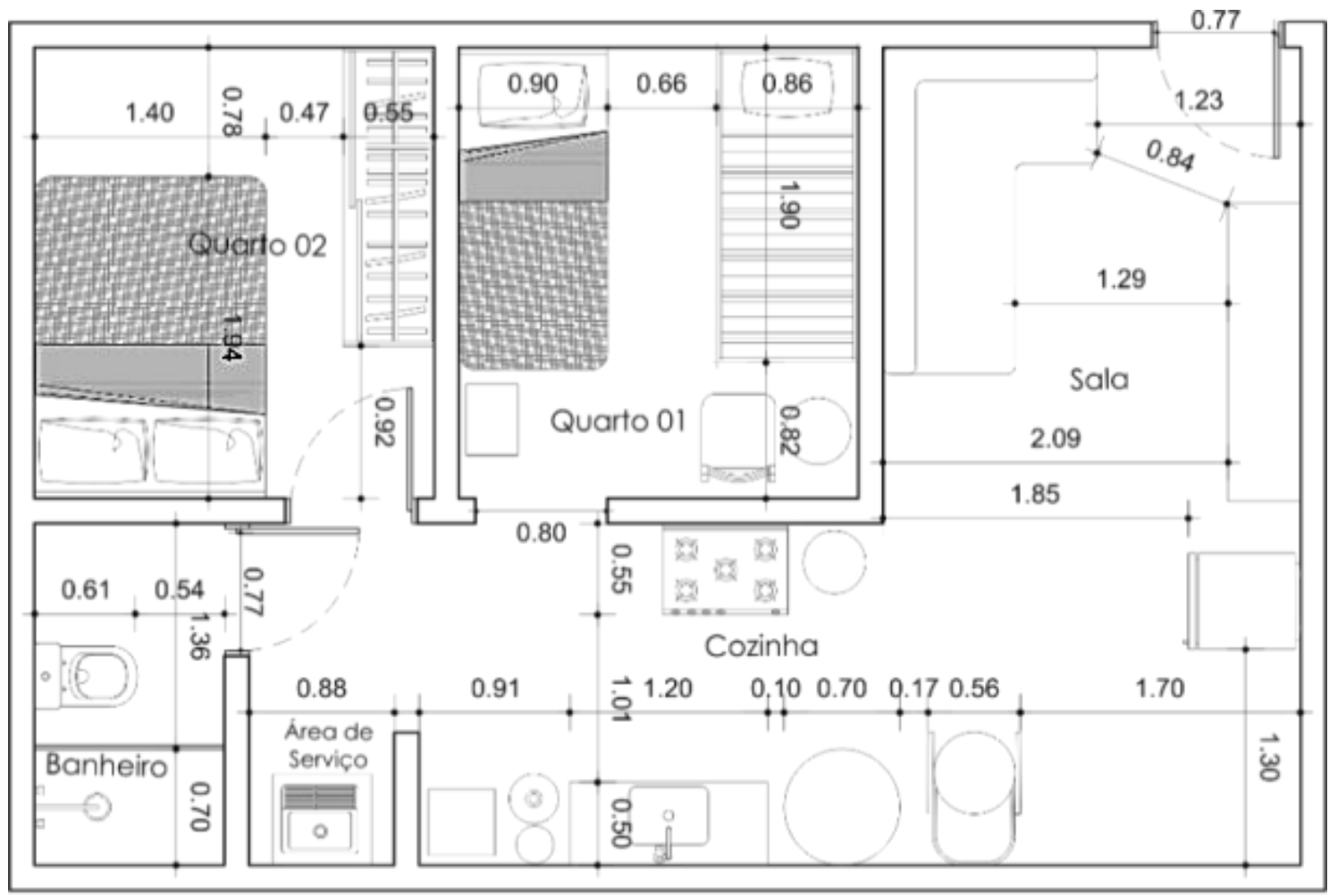

Fonte: Elaborada pelos autores para pesquisa.

Após o desenvolvimento da planta baixa com a ambientação, foi traçada a circulação realizada pelo usuário, sendo representada por uma linha na cor azul, como recomenda o MACHIA. A linha de circulação foi inserida nos ambientes necessários, isto é, ambientes no qual o usuário cadeirante utiliza com maior frequência no seu cotidiano, como: sala, cozinha, banheiro e o quarto do usuário (Figura 08). Em tempo, faz-se necessário alertar que não houve a avaliação do quarto 02 , pois não se destina ao usuário cadeirante em estudo.

Em primeiro momento, a análise foi realizada apenas com o modelo antropométrico do usuário cadeirante inserido no segmento de reta da circulação, simulando a utilização individual do ambiente (A). No segundo momento da análise foram inseridos os modelos auxiliares nos cômodos (B), a fim de analisar a circulação do cadeirante quando há a presença de outros possíveis usuários, que podem ser considerados como barreiras físicas. 


\section{策=}

Figura 08: Análise da circulação: (A) utilização individual; (B) ambiente em uso.

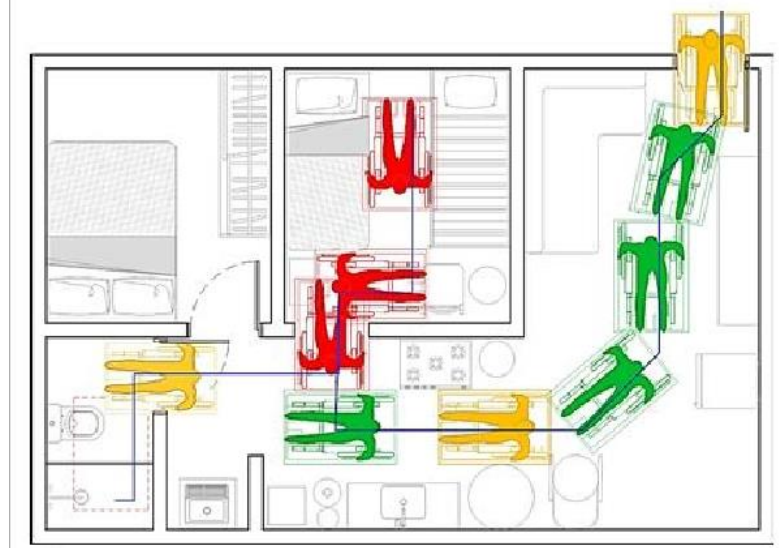

A

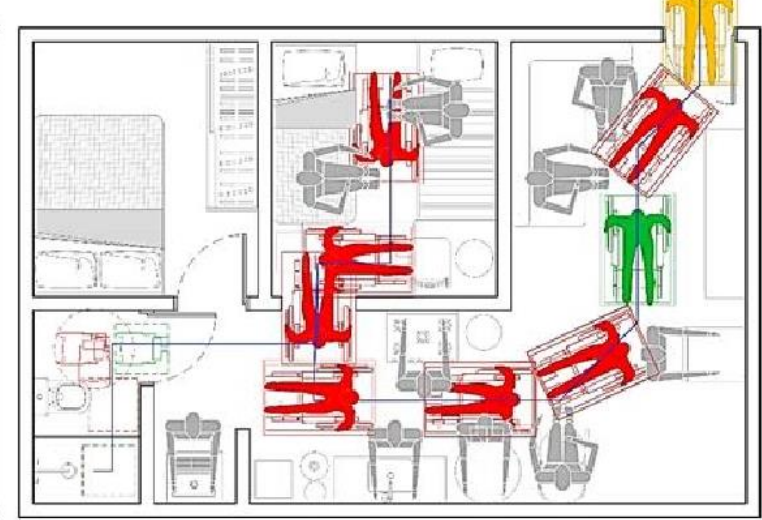

B

Fonte: Elaborado pelos autores para a pesquisa.

Analisando as áreas para circulação foram identificadas: áreas de atenção onde estão os manequins em amarelo (medidas disponíveis atingem a zona de toque), incapacidade de circulação onde estão inseridos os manequins em vermelho (medidas disponíveis ultrapassam a zona de toque) e circulação adequada onde estão os manequins em verde (medidas disponíveis não atingem a zona de toque).Com os resultados identificados pela aplicação do MACHIA e considerando as recomendações da NBR9050, foi desenvolvida uma lista de recomendações de ajustes necessários dos pontos considerados como inadequados do ambiente analisado.

Tabela 2 - Recomendações considerando a NBR 9050 e os resultados obtidos pelo MACHIA.

\begin{tabular}{|l|c|}
\hline \multicolumn{1}{|c|}{ RECOMENDAÇOES } & $\begin{array}{c}\text { Largura } \\
\text { (metros) }\end{array}$ \\
\hline Prover vão livre para passagem das portas de acesso & $0.80 \mathrm{~m}$ (mínimo) \\
\hline Proporcionar trajetos em linha reta entre um móvel e outro & $0.90 \mathrm{~m}$ (mínimo) \\
\hline $\begin{array}{l}\text { Ambientes compartilhados (sala e cozinha reunidos no mesmo } \\
\text { espaço) }\end{array}$ & $21 \mathrm{~m}^{2}$ \\
\hline $\begin{array}{l}\text { Reestruturar o corredor cozinha (considerando o fluxo de pessoas, } \\
\text { onde poderá haver outro usuário se utilizando de algum artefato, } \\
\text { considerando o conforto de ambos os usuários do ambiente) }\end{array}$ & $1.20 \mathrm{~m}$ (mínimo) \\
\hline $\begin{array}{l}\text { Oferecer circulação para o quarto do usuário, tornando possível um } \\
\text { giro de 360; }\end{array}$ & $8 \mathrm{~m}^{2}$ (mínimo) \\
\hline $\begin{array}{l}\text { Oferecer banheiros com dimensões necessárias para o uso } \\
\text { confortável e acesso ao box, considerando o módulo de referência e } \\
\text { cadeira de banho. }\end{array}$ & $3,26 \mathrm{~m}^{2}$ (mínimo) \\
\hline $\begin{array}{l}\text { Dispor de área total da edificação de forma a oferecer circulação } \\
\text { adequada }\end{array}$ & $48.8 \mathrm{~m}^{2}$ (mínimo) \\
\hline
\end{tabular}

Fonte: Elaborado pelos autores para a pesquisa.

Chegamos aos referentes valores que cada área deveria dispor através da análise das circulações inadequadas do ambiente, de modo que para cada ponto inadequado ou de atenção consideramos os centímetros necessários para que se tornasse uma circulação adequada, sempre considerando os valores do módulo de referência e da cadeira de banho. 


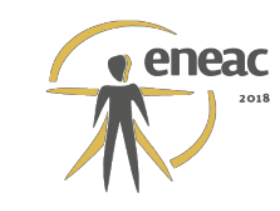

Figura 9: Proposta de alterações para o espaço.

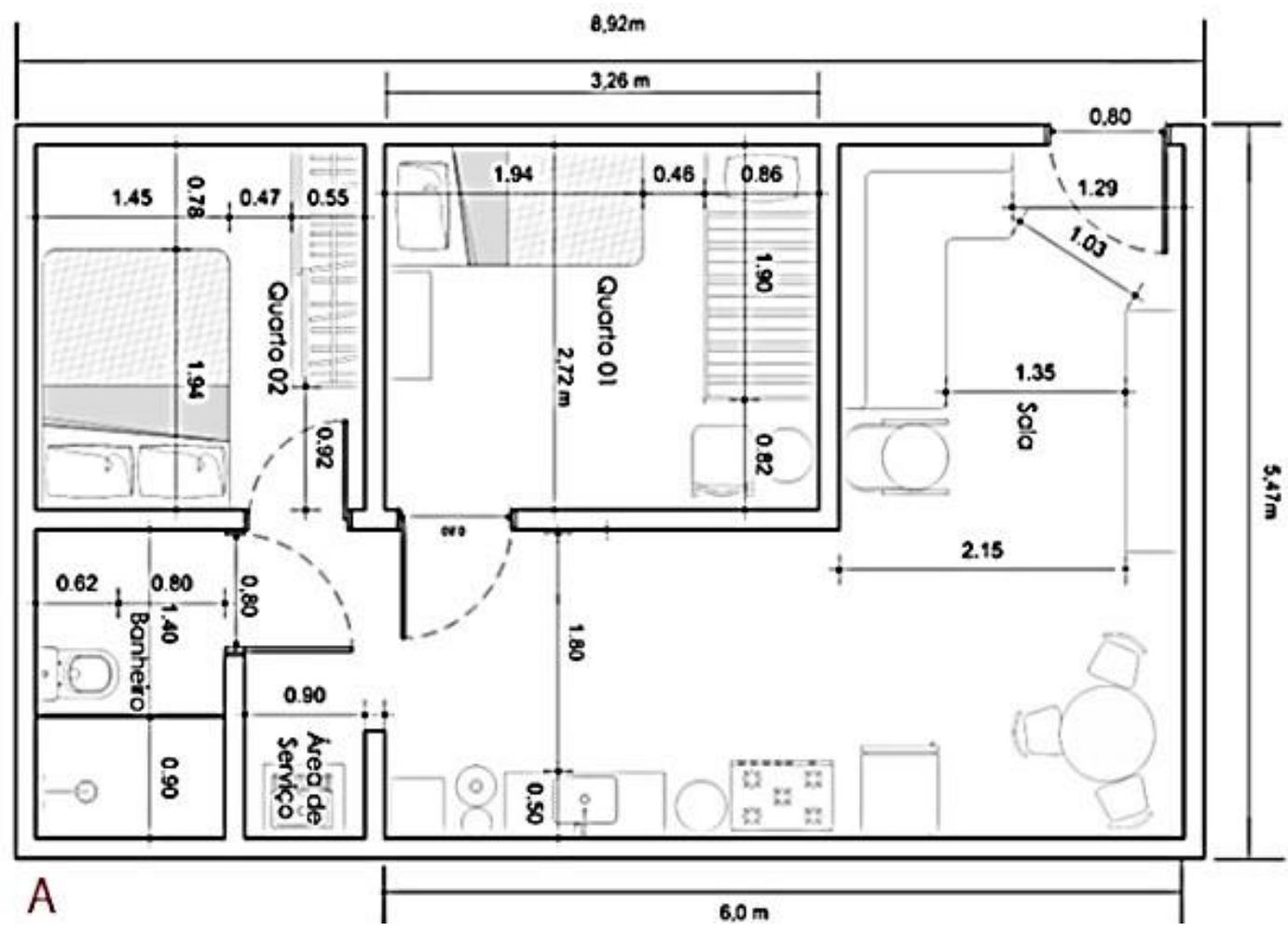

Fonte: Elaborado pelos autores para a pesquisa.

Aplicamos as recomendações na planta baixa do ambiente analisado, a fim de apresentar como a edificação deveria ser projetada para garantir a circulação adequada aos moradores (Figura 09), como também uma proposta de modelo para futuras edificações que venham ter o mesmo perfil de edificações com dimensões reduzidas (A). O MACHIA foi aplicado para verificar a circulação, sendo obtidas circulações adequadas (B).

Figura 10: Planta baixa com aplicação das recomendações (A); Aplicação MACHIA (B).

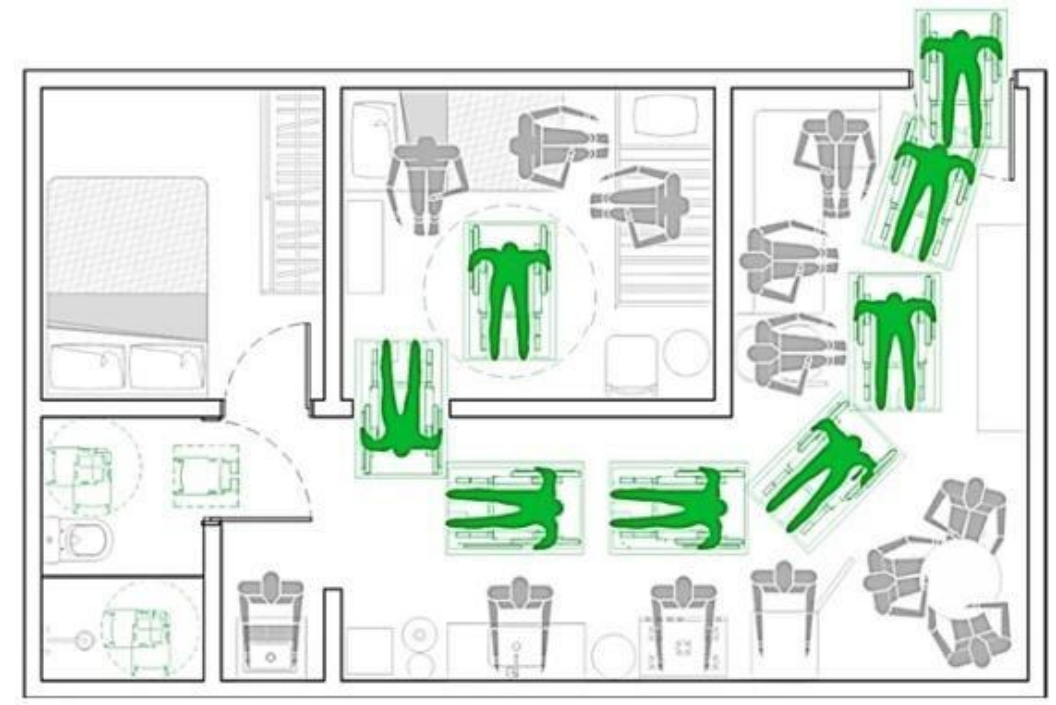

Fonte: Elaborado pelos autores para a pesquisa. 


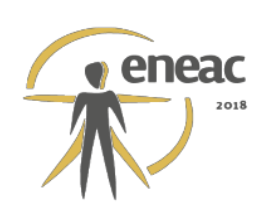

Ao analisarmos os resultados percebemos que dos 08 manequins inseridos, todos apresentaram condições adequadas para circulação, de forma a não comprometer a autonomia, segurança e conforto do usuário cadeirante e dos demais usuários. Com as dimensões do ambiente proposto, temos ambientes com dimensões mínimas que podem ser produzidos em grande escala, seja destinado para moradores cadeirantes ou que possuam outras necessidades específicas.

\section{CONCLUSÃO}

Com o estudo realizado pode-se confirmar a importância da consideração da antropometria no desenvolvimento de projetos habitacionais. Foi possível identificar que a realidade da população de baixa renda está inserida no grande grupo de cidadãos que possuem seus direitos violados, onde são concedidas moradias que não atendem efetivamente a forma de apropriação familiar, não atendendo a diferença de número de moradores para cada família e muito menos as necessidades de cada um dos moradores. O MACHIA ajudou a verificar a circulação horizontal dos espaços de forma prática e simples, de modo que possibilitou encontrar inadequações que somente com a visita ao local não seria possível identificar. $O$ método juntamente com a NBR 9050:2015, ajudou a atingir o objetivo geral, na verificação das inadequações da circulação em relação ao usuário cadeirante e na proposta de adequação funcional do ambiente.

A pesquisa nos mostra que não se pode considerar uma moradia como digna se ela não é acessível, levando em conta que ser acessível vai além do fato de estar construída no térreo de um habitacional e ter ausência de rampas. Uma moradia digna e acessível deve possibilitar aos moradores qualidade na execução de suas atividades, permitindo ao usuário, portador de algum tipo de limitação física circular em todos os ambientes possíveis com conforto e segurança, melhorando a autoestima do usuário ao lhe possibilitar autonomia. São indicadas algumas sugestões para estudos posteriores, como análises da distribuição e organização dos móveis dessas residências e análises dos novos projetos habitacionais que estão sendo construídos, além dos assuntos que não foram abordados neste trabalho, mas que poderiam ser considerados, sendo estudados em trabalhos futuros de Design visando sempre a solução de problemas presentes em nosso cotidiano. Pois acredita-se que é preciso dar visibilidade aos descasos sociais que estão sendo cometidos e maquiados como "solução do déficit habitacional", pelos programas de interesse social em nosso país.

\section{REFERÊNCIAS BIBLIOGRÁFICAS}

ASSOCIAÇÃO BRASILEIRA DE NORMAS TÉCNICAS, ABNT. NBR 9050: Acessibilidade a edificações, mobiliário, espaços e equipamentos urbanos. Rio de Janeiro, 2015.

BARROS, Bruno. Avaliação Antropométrica de Espaços de Circulação Interna de Ambientes: um método proposto. In: CIPED 2009: Congresso Internacional de Pesquisa em Design, 2009, Bauru. Congresso Internacional de Pesquisa em Design (CIPED), 2009.

Avaliação da Circulação em Salas de Aula Universitárias: um estudo de caso utilizando o MACHIA. VI Encontro Nacional de Ergonomia do Ambiente Construído - ENEAC. Recife PE, 2016. 


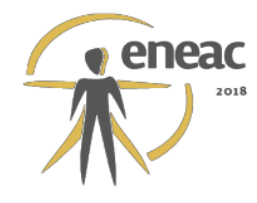

BARROS, Bruno; SEABRA, Sadi da Silva. Passo a Passo para Aplicação da Metodologia de Avaliação Antropométrica de Circulação Horizontal Interna de Ambientes. IV Encontro Nacional de Ergonomia do Ambiente Construído - ENEAC. Florianópolis - SC, 2013.

BARROS, Bruno; TAKAKI, Emika; VILLAROUCO, Vilma; DSc. Variáveis Antropométricas Relevantes no Projeto de Habitações Sociais. I Conferência Latino-Americana de Construção Sustentável x Encontro Nacional de Tecnologia do Ambiente Construído. 18-21 julho 2004, São Paulo. ISBN 85-89478-08-4.

BOUERI, José Jorge Filho. Antropometria aplicada à arquitetura, urbanismo e desenho industrial. 1를 Edição e-book, São Paulo: Estação das Letras e Cores Editora, 2008.

COHEN, R.; DUARTE, C. R. Subsídios para o Planejamento da Acessibilidade aos Espaços Urbanos. 2001. In: Anais do II Seminário Internacional Sociedade Inclusiva, PUC- MINAS.

COSTA, Ana Paula Lima. Por uma Interseção entre a Ergonomia e o Projeto de Ambientes Construídos. VI Encontro Nacional de Ergonomia do Ambiente Construído - ENEAC. Recife PE, 2016.

COSTA FILHO, L.L; MACIEL, M.L; MONTE, R; MARTINS, L.B; SOARES, M.M. (2003). APERTAMENTO: Uma Análise das Dimensões Mínimas em Apartamentos. In: ENEGEP, Ouro Preto,2003.

FOLZ, R. R. Mobiliário na habitação popular. Escola de Engenharia de São Carlos da Universidade de São Paulo. São Carlos, p. 199. 2002.

FREGOLENTE, Rosana. Caracterização da Acessibilidade em espaços públicos: A Ergonomia e o Desenho Universal contribuindo para a mobilidade das pessoas portadoras de necessidades especiais. Estudo de casos. UNESP, Bauru. 2008.

GRAEFF, Edgar Albuquerque. Edifício. Cadernos Brasileiros de Arquitetura, Volume 7. Projeto Editores Associados Ltda. São Paulo.1986.

IBGE. Instituto Brasileiro de Geografia e Estatística. Censo demográfico 2010:

Características gerais da população, religião e pessoas com deficiência 2010. Rio de Janeiro: IBGE, 2010.

IIDA, I. Ergonomia: projeto e produção. São Paulo: Blücher, 2005.

PANERO, Julius; ZELNIK, Martin. O Dimensionamento Humano para Espaços Interiores. 8ª . Ed. Mexico, D.F., Gustavo Gili, 2008.

PRADO, A. R. Unidades de Políticas Públicas. Município acessível ao cidadão. São Paulo,2001.

PROCURADORIA LEGISLATIVA. Legislação. Camera Municipal do Recife. (s.d.) Recife, PE. Disponível em: http://www.recife.pe.leg.br/legislacao. Data de acesso: 22/11/2016.

SANTOS, Aguinaldo dos; SCHMITZ SANTOS, Lisana Kátia; RIBAS, Viviane Gaspar. Acessibilidade de habitações de interesse social ao cadeirante: um estudo de caso. Ambiente Construído, Porto Alegre, v. 5, n. 1, p.55-75. 2005.

SOUZA, Jacqueline Emerich. $O$ interior da habitação popular: uma análise do arranjo do mobiliário pela ótica da Ergonomia. Instituto de Pós-Graduação de Goiânia - IPOG. Cuiabá, 2012. 